\title{
References:
}

1. Kondakov V. L., Kopeikyna E. N., Balysheva N. V., Usatov A. N. Use of gymnastic exercises of hatha yoga to increase the effectiveness of physical training. Teoryia y praktyka fyzycheskoi kultury. 2017. No 6. P. 21-23 [in Russian].

2. Matveev A. P. Metodyka fyzycheskoho vospytanyia v nachalnoi shkole: ucheb. posobye dlia stud. sred. spets. ucheb. zavedenyi [Methods of physical education in elementary school: studies. allowance for stud. n specialist. studies. institutions]. Moscow : VLADOS-PRESS, 2003 [in Russian].

3. Pryshchepa Y. M. Vozrastnaia anatomyia y fyzyolohyia : ucheb. posobye [Age anatomy and physiology: studies. allowance]. Minsk : Novoe znanye, 2006 [in Russian].

4. Suetyna O. N., Osypova Y. S. The use of elements of non-traditional health improvement in the structure of the third hour of physical culture. Vestnyk Shadrynskoho hosudarstvennoho pedahohycheskoho unyversyteta. 2016. P. 51-56. [in Russian].

\section{Dmitriieva N. S. Features of Hatha Yoga in lessons with young children of school age}

The research is devoted to the discovery of the features of the practice of hatha yoga in the classes of children of junior school age in physical culture. School age is considered to be the most important period in the process of personality formation. It is at this age that the foundation of health and development of the physical qualities necessary for effective participation in various forms of motor activity is laid and strengthened. Motor activity of children is both a condition and a stimulating factor for the development of intellectual, social, psychological and other spheres of vital activity of the child. Hatha Yoga, as a means to develop, strengthen and maintain the physical and mental properties of the human body, can solve many problems associated with the health of modern children. With the expedient use of experience and creatively approaching classes, it is possible to achieve a significant improvement in the health of children of elementary school age and to make a diverse range of their physical education classes. Yoga for children is a complex of classes based on hatha yoga, which creates all the conditions for the harmonious from the physical and mental side of the growth and development of the child's body. According to the recommendations of the author in the first stage, the asanas (physical exercises) are performed only at the level of the physical body, with control of breathing. At the second stage - you should add concentration of attention on the body area, energy centers (depending on the level of preparation). During the practice of hatha yoga, the child receives skills in managing his body, some physiological and mental processes that take place there. By fixing in the minds of children the universal values, developing their physical and emotional and volitional qualities, the practice of hatha-yoga helps the child become a harmoniously developed, creative person. Therefore, the author suggests the practice of hatha yoga to be regarded as a means of education and the necessary complement to general education.

Key words: junior school age, yoga, hatha yoga, physical culture, hatha yoga for children, physical education, child development, formation of personality, age features of the child's body.

УДК 811.161.6:378.6:37.018.43

DOI https://doi.org/10.31392/2311-5491/2019-69.14

Долгопол О. О.

\section{УДОСКОНАЛЕННЯ НАВЧАЛЬНО-МЕТОДИЧНОГО ЗАБЕЗПЕЧЕННЯ ВІРТУАЛЬНОГО ІНФОРМАЦЙНОГО СЕРЕДОВИЩА 3 ДИСЦИПЛІНИ «УКРАЇНСЬКА МОВА ЗА ПРОФЕСІЙНИМ СПРЯМУВАННЯМ»}

Стаття присвячена питанню удосконалення навчально-методичного забезпечення дисципліни «Українська мова за професійним спрямуванням». Проаналізовано навчально-методичне наповнення навчальних інформаційних середовищ, зокрема, платформи Моодlе. Встановлено, що формування мовних компетентностей досягається шляхом застосування методу вправ $і$ завдань, організації самостійної роботи. Зроблено спостереження, щзо задля формування мовленнєвої компетентності студентів у навчальному інформаційному середовищі необхідно враховувати переваги та можливості платформи Моодlе та використовувати інший інструментарій: навчальні аудіо-, відеоматеріали, проблемні завдання та ситуаиії професійного спрямування, що потребують вирішення шляхом організації діалогічного та полілогічного мовлення між учасниками навчального процесу (викладач - студент, студент - студент, викладач студенти, студенти - студенти). Враховуючи наукові дослідження з проблеми, практичний досвід зі створення та наповнення віртуального інформаційного середовища висловлено пропозииії щзодо удосконалення наповнення навчально-методичного забезпечення платформи Моодlе. Приділено увагу ролі та функціям викладача під час розроблення та керування електронним курсом. Відображено питання контролю та оцінювання роботи студентів у навчальному інформаційному середовищі. Рекомендовано пропозищї щцодо навчально-методичного наповнення віртуального навчального середовища конкретними завданнями з дисципліни з урахуванням специфіки фаху студентів.

Ключові слова: навчально-методичне забезпечення, украӥнська мова за професійним спрямуванням, віртуальне інформаційне середовище, інформаційний простір навчання мови, віртуальне навчальне середовище Моодlе, відкрите навчальне середовище, викладання украйнської мови за професійним спрямуванням, методи навчання мови.

Проблема навчально-методичного забезпечення дисциплін постійно перебуває під посиленою увагою викладачів. Адже педагогічна аксіома звучить: від якості навчально-методичного забезпечення залежить успішність студентів. Із переорієнтацією навчального простору на Інтернет, 3 появою інформаційних навчальних середовищ постало питання їх якісного методичного наповнення. Вирішення цієї проблеми 
допоможе більш мотивувати студентів до навчання, як результат, підвищить якість навчання. Тож наразі гостро стоїть питання методичного забезпечення інформаційного середовища кожної навчальної дисципліни.

Наповнення навчальних інформаційних середовищ відображає орієнтацію сучасної педагогічної науки на потреби особистості майбутнього спеціаліста, враховуючи його запити і мотиви. За допомогою віртуальних навчальних середовищ більшість студентів оволодівають необхідним мінімумом знань. Мета дисципліни «Українська мова за професійним спрямуванням» - сформувати у майбутнього фахівця необхідну для успішного виконання професійних завдань мовну і мовленнєву компетентності, що неможливо лише через виконання вправ і завдань без діалогічного та полілогічного складників. Тож під час розроблення методичного забезпечення дисципліни викладачам слід враховувати цю особливість дисципліни.

Метою статті $\epsilon$ аналіз стану методичного забезпечення інформаційного середовища дисципліни «Українська мова за професійним спрямуванням» та наукове розроблення пропозицій щодо його вдосконалення.

3 появою перших інформаційно-комунікаційних технологій у навчальному процесі (телефонних засобів зв'язку, телебачення) їх використання стало предметом наукових досліджень українських учених В. Ю. Бикова, Я. В. Булахової, О. М. Бондаренко, В. Ф. Заболотного, Г. О. Козлакової, О. А. Міщенко, О. П. Пінчук, О. В. Шестопал та інших. Наступний крок в опануванні новітніх технологій навчання за допомогою Інтернету належить мережевим технологіям навчання. Їх дослідженню присвячено праці С. Пейперта, А. А. Андрєєва, Є. С. Полат, М. І. Жалдака, Н. В. Морзе, С. А. Ракова, В. В. Олійника, В. Ю. Бикова, В. М. Кухаренко та інших учених. Ближчими до нашої проблеми стоять праці Т. Л. Архіпової, Л. І. Білоусової, В. В. Бикова, А. Ф. Верлань, О. М. Гончарової, А. М. Гуржій, Ю. О. Жук, С. А. Ракова та інших, в яких порушується питання не тільки розроблення та застосування засобів на основі інформаційних технологій, а й методичної підтримки щодо їх використання. Дослідники О. В. Кареліна, Д. Р. Денисов, Н. В. Баловсяк, Т. Б. Поясок, Т. І. Коваль розглядають питання використання інформаційних технологій в професійній підготовці економістів, спеціалістів ресторанного обслуговування, бухгалтерів та формування їх інформаційної компетентності, у тому числі, порушуючи проблему якості навчально-методичного забезпечення інформаційного середовища дисциплін, що викладаються фахівцям зазначених спеціальностей. Активно досліджуються освітні можливості інформаційного середовища Moodle, яке вважається на сьогодні одним із перспективних для впровадження мережевих технологій систем управління навчанням LMS (Learning Management Systems). Проблеми його впровадження та використання розглядають М. Дугіамос, П. Якушев, А. Носуленко, А. Попов, А. Андрєєв, Т. Бокарєва, І. Доценко, Т. Мяснікова, В. Богомолов та інші. Незважаючи на значну кількість досліджень, присвячених окремим аспектам інформатизації процесу професійного навчання, у зв’язку з виявленою специфікою фаху, що виражається в необхідності введення до інформаційного середовища навчання з української мови за професійним спрямуванням діалогічного та полілогічного складників, потребує уваги питання навчально-методичного забезпечення інформаційного середовища цієї дисципліни.

У безперечних перевагах використання комп'ютерів, мережевих технологій, Інтернету не потрібно переконувати. Зараз сучасні студенти вправно послуговуються усіма надбаннями науково-технічного прогресу $\mathrm{i}$ вміють швидко шукати необхідну інформацію в Інтернеті, обробляти їі та інтерпретувати, вони навчаються за допомогою окремих інтернет-ресурсів, листуються за допомогою завантажених до гаджетів сучасних програм, активні в комунікації у соціальних мережах, а дехто з них уміє створювати програмні продукти різної складності та гатунку. Тож цілком закономірним є бажання викладацької спільноти мотивувати студентів до навчання, залучаючи їх до знайомих і цікавих інтернет-технологій.

«Інформаційне освітнє середовище», «інформаційний простір навчання», «віртуальне навчальне середовище», «відкрите навчальне середовище» - терміни-синоніми на позначення інтернет-навчання, що зараз набули популярності завдяки багатьом перевагам, зокрема, через інтерактивність, що закладена у побудові механізмів взаємодії учасників навчання [3, с. 104]. Тож із-поміж інших термінів на позначення активної взаємодії суб'єктів навчального процесу в інтерактивному режимі за допомогою мережевих технологій будемо послуговуватися терміном «віртуальне інформаційне середовище». Це «єдиний відкритий інтерактивний інформаційний освітній простір, побудований на мережевій технології, що містить: навчальну інформацію та інформацію з результатами навчальної діяльності, представлену 3 допомогою оптимально-структурованого навчально-методичного комплексу; розширений апарат дидактики, в якому діють принципи інноваційної педагогіки; системи управління навчальним процесом та навчальним контентом, середовище для реалізації процесу навчання» [5, с. 116].

Наразі багато закладів вищої освіти (далі - 3ВО) України послуговуються можливостями такого навчання за допомогою модульного об'єктно-орієнтованого динамічного навчального середовища (Moodle).

Аналіз навчально-методичного забезпечення інформаційного середовища Moodle більшості 3ВО демонструє традиційний підхід до наповнення платформи дидактичними матеріалами: тексти лекцій, методичні рекомендації до практичних занять за темами, методичні рекомендації до самостійної роботи 3 відповідними завданнями, вправами, задачами тощо. Увага викладачів-філологів спрямована на забезпечення інформаційного середовища навчальними матеріалами у вигляді схем, таблиць, вправ, завдань, тестів, тем для письмових робіт тощо, тобто викладачі-мовники користуються арсеналом дидактичних прийомів, методів 
і форм роботи, спрямованих на формування мовної компетентності майбутніх спеціалістів. Сформованої мовленнєвої компетентності цим інструментарієм не досягти. Тож перед філологами, які працюють в інформаційному середовищі, стоїть складне завдання: забезпечити інформаційну навчальну платформу такими матеріалами, що сприятимуть формуванню мовленнєвої складової компетентності майбутнього спеціаліста; і як супутне, додаткове завдання: зробити процес навчання студентів у цьому просторі мотивованим, цікавим та максимально професійно спрямованим, що можливо завдяки дібраним навчально-методичним матеріалам та завданням.

Сьогодні більшість викладачів компетентні у тому, щоб забезпечити дисципліну, яку викладають, навчально-методичними матеріалами в електронному форматі, створити мультимедійну презентацію, електронний підручник чи посібник тощо. Від таких дій виграють обидві сторони: викладач, який надає студентам весь необхідний арсенал знань у електронному форматі, студент, який, маючи доступ до платформи, де розміщено матеріали, у зручний для нього час може скористатися ними у повному обсязі.

Дослідники проблеми стверджують, що ефективність формування ключової або спеціальної фахової компетентності майбутніх фахівців засобами мережевих технологій істотно залежить від таких чинників: по-перше, від програмного забезпечення, від можливостей, які надають розробники адміністраторам в межах електронної платформи; по-друге, від навчально-методичного забезпечення наповнення курсу, по-третє - від суб’ єктів навчання, їх компетентності (викладач) та мотивованості (студент) [4, с. 183]. Друге - відображення творчості викладача, його компетентностей, якщо можна так сказати, це на сьогодні один із показників рівня педагогічної майстерності, методичної грамотності, уміння мотивувати студентів тощо.

Навчально-методичні матеріали з української мови за професійним спрямуванням в інформаційному середовищі Moodle сприяють залученню студентів до активного дослідження, адже розвивають уміння спілкуватися на професійні теми, вирішувати складні професійні завдання, будувати діалоги на професійні теми, вирішувати конфліктні ситуації шляхом добору інструментів аргументації, злагоджено працювати в команді, орієнтуватися в ситуаціях спілкування через цікаві та складні завдання, що допомагають формувати та розвивати комунікативні (мовленнєві) компетентності.

Для прикладу можна навести давно і активно застосовувані викладачами засоби мультимедіа. Електронна платформа дає можливість завантажити та використовувати у навчанні електронні лектори, тренажери, підручники, енциклопедії, ситуаційно-рольові та інтелектуальні ігри (у тому числі, з використанням штучного інтелекту), а також моделювати процеси і явища, забезпечити інтерактивні освітні телеконференції, побудувати систему контролю й перевірки знань і умінь студентів (використання контролюючих програмтестів), здійснювати проєктивну та дослідницьку діяльність студентів, створювати web-сторінки, надавати посилання на файли, каталоги, аудіо та відео матеріали, тренінги, навчаючі програми, створювати презентації навчального матеріалу. Як показує практика, викладачі послуговуються навіть не всіма можливостями презентацій РowerPoint.

Задля удосконалення навчально-методичного забезпечення 3 дисципліни «Українська мова за професійним спрямуванням» до віртуального інформаційного середовища, на нашу думку, окрім традиційних файлів 3 дидактичними матеріалами, варто додати кілька розділів. «Вимоги» - розділ для студентів із вимогами навчальної програми до рівня компетентностей з дисципліни та зазначенням форм контролю і критеріями оцінювання знань, умінь та навичок студентів. «Схеми розборів» - розділ інформаційного середовища, де студентам запропонувати узагальнені схеми фонетичного, лексичного, синтаксичного та інших розборів 3 прикладами різної складності. Самостійне ознайомлення з інформацією цього розділу слугуватиме підгрунтям для тематичного та модульного контролів. «Розумові дії» - розділ, в якому зібрати професійні ситуації, що вимагають мовленнєвої діяльності майбутнього фахівця, наприклад, спеціалісту-екологу потрібно проаналізувати та надати усні пояснення з приводу виявлених у ході перевірки об'єкта порушень, або фахівцю з тепломереж усно класифікувати матеріали, з яких виготовлено споруди, навести аналогії тощо. «Фотогалерея» - розділ, який постійно поповнювати завдяки спостережливості самих студентів, у ньому зібрати фото з зображенням порушення мовних норм на рекламній продукції, плакатах, біг-бордах, у роздатковому матеріалі, газетних i журнальних статтях, а також скріншоти з соціальних мереж. Завдання студентам: не лише віднайти помилки і зредагувати мовний матеріал, але й поповнити розділ власними знахідками, а значить, виховати пильність та увагу до мови і мовлення. «Кінозал» - найбільш цікавий для студентів розділ середовища, в якому представити відеоролики 3 мультфільмів, художніх фільмів, пов’язані з етикою поведінки, зокрема, в професійній сфері. Після перегляду студентам запропонувати різні за складністю завдання: від складання і програвання правильних 3 погляду етики діалогів і аналізу поведінки головних героїв сюжетів до участі у дидактичній грі 3 використанням мовленнєвих конструкцій, що були у переглянутому фрагменті. «Практика»-розділ середовища, в якому підібрати мовленнєві вправи (наголос у слові, логічний наголос у реченні, інтонація, підбір синонімів, антонімів, інші вправи). «Опора» - розділ інформаційного середовища, в якому у таблицях і схемах зібрати основні відомості з основ риторики, стилістики, синтаксису тощо. «Література» - розділ, в якому представити оновлений перелік літературних та інтернет-джерел із посиланнями за темами курсу. «Експеримент» - розділ, що містить експериментальні завдання для виконання вдома. Це теми для есе, повідомлень, рефератів 3 вимогами до їх створення і публічного захисту. «Історія»- невеликий розділ з підібраними архівними матеріалами щодо мовної політики у різні часи існування нашої держави, про розвиток мовознавства та вчених, які рухали 
цю галузь. Як показує практика, така інформація є досить цікавою студентам, вони охоче 3 нею знайомляться. «Контроль» - розділ, в якому представлені завдання для вхідного, поточного, підсумкового контролю 3 тем курсу. Середовище під позначкою «?» передбачає зворотній зв'язок, у ньому зібрано питання, що виникають у студентів під час роботи з навчально-методичними матеріалами. «Інтерес» - розділ, що є необов'язковим, але бажаним, бо містить матеріали, що знадобляться студентам під час проходження співбесіди, пошуку роботи, складання резюме. Наприклад, є завдання, що передбачають складання зв'язної розповіді про майбутній фах, про перспективи, про освіту, про набуті власні компетентності тощо.

Однозначно, можна говорити про зміну ролі викладача інформаційному навчальному середовищі. Викладач виступає не в ролі передавача готових знань студентам, а виконує роль консультанта, керівника, який «опосередковано організує та стимулює учасників навчальної діяльності» [2, с. 13], комбінуючи традиційні та мережеві форми навчання та допомагає студентам самостійно формувати мовні та мовленнєві компетентності. Викладач має змогу проводити інтерактивні мережеві заняття та викладати фрагменти їх відеозаписів у відповідний розділ платформи. Протягом заняття викладач у змозі змінювати напрями дискусій та обговорення професійних питань, відточуючи у студентів лексичний склад фахової мови. Спілкування студента з викладачем та іншими студентами відбувається опосередковано, в режимі реального часу або через певні часові проміжки. При цьому викладач не відстороняється, а, навпаки, активно бере участь у навчальному процесі, коментуючи та коректуючи поточну роботу учасників навчальної діяльності.

Висновки. Беззаперечним є той факт, що за мережевими освітніми технологіями, віртуальними освітніми середовищами майбутнє, оскільки вони мають переваги перед класичним навчанням. Однією 3 позитивних ознак віртуального інформаційного середовища є посилення самостійності в навчанні студентів, що вповні відображає сучасну парадигму навчання. Завдання викладачів, функції яких у такому форматі навчання радикально змінюються, зробити процес набуття студентами компетентностей цікавим, професійно спрямованим, корисним. Це досягається шляхом ускладнення вимог до змісту та форм самостійної роботи, залучення студентів до самоорганізації в навчанні, переводом умінь на рівень самоосвіти, науково обгрунтованим та вмотивованим відповідно до мети навчальної дисципліни навчально-методичним забезпеченням електронного змісту курсу. Дотримання таких пріоритетів є додатковою мотивацією для прояву студентської активності у напрямі особистісного професійного спрямування. Перспективним у віртуальному інформаційному середовищі є метод проєктів, проблемний, навчання у співробітництві, метод портфоліо. Їх реалізація стане темою для подальших наукових розвідок.

Використана література:

1. Костриця Н. Пошуки нових форм проведення занять з української мови у вищій школі на нефілологічних факультетах. Українська мова та література в школі. 2014. № 3. С. 53-54.

2. Равчина Т. Організація взаємодії студентів з освітнім середовищем у вищій школі. Вісник Львівського університету: Серія : «Педагогічна». 2005. Вип. 19. Ч. 2. С. 4-16.

3. Триус Ю., Герасименко I., Франчук В. Система електронного навчання BH3 на базі MOODLE : методичний посібник / за ред. Ю. Триуса. Черкаси, 2012. 220 с.

4. Щолок О. Інформаційно-навчальне середовище як чинник формування компетентності самоосвіти у майбутнього фахівця. Освітнє середовище як методична проблема : зб. наук. пр. Херсон : Видавництво ХДУ, 2006. С. $183-184$.

5. Büchner A. Moodle 3 Administration. Third Edition. Packt Publishing, 2016. 492 c.

\section{References:}

1. Kostrytsia N. Poshuky novykh form provedennia zaniat $\mathrm{z}$ ukrainskoi movy u vyshchii shkoli na nefilolohichnykh fakultetakh. Ukrainska mova ta literatura v shkoli. 2014. № 3. S. 53-54 (in Ukrainian).

2. Ravchyna T. Orhanizatsiia vzaiemodii studentiv z osvitnim seredovyshchem u vyshchii shkoli. Visnyk Lvivskoho universytetu: ser.: Pedahohichna. 2015. Vyp. 19. Ch. 2. S. 4-16 (in Ukrainian).

3. Tryus Yu., Herasymenko I., Franchuk V. Systema elektronnoho navchannia VNZ na bazi MOODLE : metodychnyi posibnyk / za red. Yu. Tryusa. Cherkasy, 2012. 220 s. (in Ukrainian).

4. Shcholok O. Informatsiino-navchalne seredovyshche yak chynnyk formuvannia kompetentnosti samoosvity u maibutnoho fakhivtsia. Osvitnie seredovyshche yak metodychna problema : zb. nauk. pr. Kherson : Vydavnytstvo KhDU. S. 183-184 (in Ukrainian).

5. Büchner A. Moodle 3 Administration. 3rd ed. Packt Publishing, 2016. 492 s. (in English).

Dolgopol O. O. Improvement of education-methodic for the virtual informational media from the discipline "Ukrainian for Specific Purposes"

The article is devoted to the actual issue of improving the teaching and methodological support of the discipline "Ukrainian for Specific Purposes». The educational and methodological content of educational information media, in particular, the platform Moodle, is analyzed. It is established that the formation of speech competences is achieved by applying the method of exercises and tasks, organizing independent work. It has been observed that other tools need to be used to form the speech competence in the educational information environment. Taking into account the advantages and potential of the virtual learning environment of Moodle for the formation of the speech competence of future specialists, the use of educational audio and video materials, problem tasks and situations of a professional direction, which requires solving by organizing dialogue and polylogical speech between the participants of the educational process (teacher-student, student-student, teacher-students, students - students). The attention was paid to the role and functions of the teacher in the development and management of the electronic course. The results of implementation of these tasks in the educational process are analyzed. Refers the question 
of monitoring and evaluating students'work in the educational information environment. The proposals on the teaching and methodological filling of the virtual learning environment with specific tasks in the discipline, taking into account the specifics of the specialty of students, have been developed and recommended.

Key words: vocational guidance in Ukrainian, virtual information environment, language learning information space, virtual learning environment Moodle, open learning environment, teaching the Ukrainian language in a professional way, language teaching methods.

УДК 378.937

DOI https://doi.org/10.31392/2311-5491/2019-69.15

Железняк О. В., Цокур О. С.

\section{РЕЗУЛЬТАТИ ЕКСПЕРИМЕНТУ 3 ФОРМУВАННЯ ПЕДАГОГІЧНОГО ПРОФЕСІОНАЛІЗМУ МАЙБУТНІХ ФАХІВЦІВ РОМАНО-ГЕРМАНСЬКОЇ ФІЛОЛОГІЇ ЯК СУБ'ЄКТІВ ТА ОРГАНІЗАТОРІВ ГЕНДЕРНОЇ ОСВІТИ УЧНІВСЬКОЇ МОЛОДІ}

Стаття присвячена висвітленню результатів експерименту з формування педагогічного професіоналізму майбутніх фахівців романо-германської філології як суб'єктів та організаторів гендерної освіти учнівської молоді. У процесі дослідження з'ясовано сутність і структуру педагогічного професіоналізму майбутніх фахівиів романо-германськоі філології як суб'єктів та організаторів гендерної освіти учнівської молоді, уточнено критерї і показники виміру його рівнів. Проаналізовано емпіричні дані трьох діагностичних зрізів щзодо динаміки формування означеного феномена, узагальнено їх результати.

3'ясовано, щзо педагогічний професіоналізм фахівиів романо-германської філології як суб'єктів та організаторів гендерної освіти учнівської молоді - ие кваліфікаційна характеристика, щзо забезпечує успішність їх професійної діяльності у сфері освітніх послуг на підставі коректного впровадження принципів гендерного підходу шляхом оволодіння необхідними світоглядними настановами й предметними компетенціями, гнучкими способами виконання професійних завдань і відповідними психологічними установками, мотиваціями.

Продемонстровано, щзо педагогічний професіоналізм фахівців романо-германської філології як суб'єктів та організаторів гендерної освіти учнівської молоді є провідним освітнім результатом їхньої иілеспрямованої фахової підготовки. Це складноструктуроване новоутворення особистості фахівиів романо-германської філології як менеджерів гендерованого освітнього середовища, яке віддзеркалює їх гендерну чутливість до будь-яких порушень прав $і$ свобод людини, належну педагогічну кваліфікаиію і гендерну грамотність щодо запобігання ризикам насильства та дискримінаиії осіб за ознакою статі (сексизму, булінгу), гендерну толерантність, гнучкість і різноманітність ефективних способів нівелювання застарілих гендерних стереотипів, щцо дає змогу з високою стабільною продуктивністю вирішувати навчально-виховні завдання згідно з ідеями гендерної рівності.

Ключові слова: професійна підготовка, майбутні фахівиі романо-германської філології, гендерний підхід, педагогічний професіоналізм, гендерна чутливість, гендерна грамотність, гендерна толерантність.

Дотримання європейських стандартів якості вищої освіти фахівців романо-германської філології (Моdern Languages: Learning, Teaching, Assessment [2], Education: Moving into the New Era [6], European Language Portfolio: Principles and Guidelines [7]) зумовлює необхідність приведення змісту, форм і методів їхньої фахової підготовки у відповідність до нових вимог. При цьому визнається, що однією з провідних тенденцій розвитку сучасної професійної освіти фахівців романо-германської філології є іiї подальша демократизація й гуманізація [8, с. 41] на засадах альтернативних - гендерного й мультикультурного [5, с. 462] підходів. У зв'язку з цим у вітчизняній теорії та практиці педагогіки вищої школи значно актуалізувалася проблема підготовки фахівців романо-германської філології як суб'єктів та організаторів гендерної й мультикультурної освіти учнівської молоді [4, с. 79].

Прийняття урядами європейських країн, включно з Україною, стратегії гендерної рівності як складника всіх державних документів, що стосуються нормативно-правового забезпечення найважливіших соціальних програм і першочергових освітніх проєктів [1], значно актуалізувало проблему гендеру в педагогіці. Це сприяло тому, що із середини 90-х років минулого століття в Україні значно активізувалися дослідження 3 теорії та методології гендеру (І. Горошко, Г. Лактіонова, Л. Лобанова, Л. Міщик, М. Скорик, Л. Смоляр); упровадження принципів гендерної рівності та демократії у сферу освітнього простору сучасної вищої школи (М. Згуровський, Я. Кічук, Л. Кобелянська, Т. Мельник, С. Харченко); інтеграції гендерного підходу у вищу професійну та педагогічну освіту (Т. Голованова, Т. Дороніна, О. Железняк, І. Іванова, О. Любарська, О. Цокур); гендерної психології та педагогіки (Т. Говорун, О. Кікінежді, В. Кравець, О. Луценко); гендерної соціалізації й гендерного виховання учнівської та студентської молоді (С. Вихор, Н. Єрофеєва, Л. Зверєва, О. Каменська, О. Кізь, Л. Надолинська, А. Шевченко).

Однак проблема формування й розвитку професійної компетентності фахівців романо-германської філології як суб’єктів та організаторів гендерної освіти учнівської молоді до сьогодні залишається дискусійною. Причиною тому є суперечності між: потребою українського суспільства в освітянах, здатних ефективно 